\title{
Expansão da agroindústria canavieira e qualificação da mão-de-obra em Goiás (2006-2013)
}

\section{Growth of sugarcane agroindustry and qualification of labor in Goiás (2006-2013)}

Fernando Campos Mesquita Universidade Estadual de Campinas - UNICAMP, Campinas, São Paulo, Brasil. fernandocmesquita@gmail.com

André Tosi Furtado Universidade Estadual de Campinas - UNICAMP, Campinas, São Paulo, Brasil. furtado@ige.unicamp.br

Artigo recebido em 24/07/2015 e aceito para publicação em 20/06/2016

RESUMO: A agroindústria canavieira em Goiás conviveu, durante o auge de sua expansão na segunda metade da década de 2000, com um "gargalo" relacionado à falta de mão de obra qualificada. Essa situação ocorreu na medida em que o avanço nos projetos de mecanização e as particularidades do cultivo da cana-deaçúcar nas condições naturais de Cerrado exigiam trabalhadores que a região não estava preparada para fornecer. Trazer esses profissionais de fora - em geral, de São Paulo - acarretava em aumento dos salários e na consequente redução da rentabilidade dos investimentos. Ademais, havia o problema de poucos deles se adaptarem às pequenas cidades do interior de Goiás, onde se instalaram as usinas. Nosso objetivo é analisar os mecanismos que permitiram à região minimizar os efeitos da ausência de mão de obra qualificada, apoiando o desenvolvimento da agroindústria canavieira. $\mathrm{O}$ artigo discorre sobre a expansão da produção de açúcar e etanol em Goiás entre 2006 e 2013 e como criou-se uma demanda e oferta por mão de obra apta ao trabalho nas usinas.

Palavras-Chave: Agroindústria canavieira; mão de obra qualificada; instituições de ensino e pesquisa.

ABSTRACT: Sugarcane agroindustry in the state Goiás, during the moment of boom in the second of the 2000s, had to deal with an obstacle related to the lack of skilled labor. It occurred insofar as mechanization projects moved forward and the conditions of producing in Brazilian Savannas brought the necessity of workers that the region was not able to provide. Hiring them from other regions, especially São Paulo, increased wage costs and affected investments profitability. Moreover, few were adapted to the lifestyle of Goiás ' small cities where sugarcane-processing plants are located. Our aim is to analyze the mechanisms that allowed the region to overcome the absence of qualified labor, supporting the development of sugarcane agroindustry. The paper discusses the growth of ethanol and sugar production in Goiás between 2006 and 2013. Thereafter, we show how it influenced the creation of a demand and supply of workers with the skills required in this activity.

Key-Words: Sugarcane Agroindustry; qualified labor; teaching and research institutions.

DOI: http://dx.doi.org/10.1590/1982-451320160105 


\section{INTRODUÇÃO}

A carência de mão-de-obra qualificada em Goiás é uma preocupação recorrente para a agroindústria canavieira. É comum, tanto no meio acadêmico (LIBONI, 2009; YAMADA, 2014) quanto na imprensa (GLOBO RURAL, 2014), que esse seja apontado como um dos principais "gargalos" que as usinas enfrentam na região.

Diferentemente do que predominou nos momentos em que o plantio e a colheita eram manuais e as condições edafoclimáticas favoráveis - como nos casos da zona da mata nordestina e nas regiões de "terra roxa" de São Paulo -, a cana-de-açúcar, ao migrar para Goiás na segunda metade da década de 2000, presencia uma fase marcada pela mecanização e o cultivo em condições adversas. Mudança, essa, que acarreta no aumento da exigência por profissionais de maior qualificação.

Criaram-se "oportunidades para tratoristas, motoristas, mecânicos, condutores de colheitadeiras, técnicos em eletrônica, dentre outros, e reduz, em maior proporção, a demanda dos empregados de baixa escolaridade" (MORAES, 2007, p. 610). Ademais, as condições edafoclimáticas do Cerrado, com o longo período sem chuvas e a ocupação de solos com baixa fertilidade, aumenta a procura, sobretudo por agrônomos, na medida em que o comportamento da cana-de-açúcar nesse ambiente era pouco conhecido. Fazia-se necessário profissionais aptos a absorver e adaptar técnicas modernas de cultivo e planejar o manejo da fase agrícola.

Adquirir essa mão de obra seria um desafio. Goiás não dispunha de trabalhadores com essa qualificação, ao menos, não na proporção que o setor exigia. Trazê-los de fora, de regiões onde a cana-deaçúcar estava mais consolidada, não era viável na medida em que, de um lado, a contratação desses profissionais exigia elevar os salários, reduzindo a rentabilidade dos investimentos e, de outro, eles precisavam se readequar às condições de produzir em Goiás. Ao mesmo tempo, havia o problema da adaptação aos modos de vida locais, já que muitas das usinas foram instaladas em pequenas cidades do interior do Estado, onde serviços de lazer, saúde e educação eram escassos.
Mesmo diante dessa situação, Goiás, nos últimos anos, se tornou uma das regiões mais dinâmicas para a produção de cana-de-açúcar. Os índices de produtividade estão nos mesmos patamares que os de São Paulo; novas técnicas avançam com a incorporação de práticas locais; o melhoramento genético, por parte do Instituto Agronômico de Campinas (IAC) e do Centro de Tecnologia Canavieira (CTC), tem influência do diálogo com os técnicos das usinas locais, enquanto, o da Rede Interuniversitária para o Desenvolvimento do Setor Sucroenergético (Ridesa), já está sendo desenvolvido internamente.

Esse avanço se reflete no setor produtivo. O Estado de Goiás, no começo da década de 2010, tornou-se o segundo maior produtor de etanol e de cana-de-açúcar do país (UNICA, 2015).

O objetivo do artigo é analisar os mecanismos que permitiram a Goiás lidar com a ausência de mão de obra qualificada, possibilitando às usinas os atuais patamares de desenvolvimento. Esse foi um ponto essencial para que o crescimento da cana-deaçúcar fosse um processo tanto horizontal (com a expansão de área) quanto vertical (com o aumento da produtividade).

O caminho percorrido para atingir nossas conclusões pautou-se no estudo de dados sobre o emprego formal na agroindústria canavieira em Goiás. Utilizamos a Relação Anual de Informações Sociais (Rais) para indicar o quanto aumentou o número de funcionários com curso superior no setor entre 2006 e 2013. Para o estudo da qualificação da mão de obra, olhamos para os grupos de pesquisa, universidades e os cientistas locais vinculados à cana-de-açúcar. Nessa parte, colabora o uso do Diretório dos Grupos de Pesquisa do Brasil e Painel Lattes, ambos vinculados ao Conselho Nacional de Desenvolvimento Científico e Tecnológico (CNPq).

A análise dos resultados foi influenciada pelas informações obtidas no trabalho de campo desenvolvidoparanossatese de doutoramento, quando vistamos cinco usinas em Goiás e dialogamos com pesquisadores do IAC, CTC e Ridesa (MESQUITA, 2015).

O ponto de partida do artigo está em uma discussão teórica sobre o papel da mão de obra 
qualificada na modernização da agricultura e em duas relações espaciais que esse processo assume: uma, no tocante a fatores de reprodução, outra, referente à atração da mão de obra. Em seguida, contextualizamos, brevemente, a expansão da agroindústria canavieira em Goiás entre 2006 e 2013. O próximo passo foi associar o crescimento do setor à geração local de empregos com maior qualificação e aos índices de produtividade da cana-de-açúcar. Por fim, trazemos os resultados de nossa análise sobre os esforços locais que tem permitido à região fornecer esses trabalhadores para as usinas.

\section{M Ã O-D E - O B R A Q U A L I F I C A D A E AGRICULTURA: FATORES DE REPRODUÇÃO E ATRAÇÃO}

Schultz (1965) foi um dos pioneiros no sentido de apontar a importância da mão de obra qualificada para a agricultura. A ideia aparece na busca do autor - em momentos iniciais de disseminação na escala global do padrão técnico-produtivo que mais tarde seria conhecido como "Revolução Verde" (SALLESFILHO, 2005, p. 10) - por compreender as razões por trás do rompimento da barreira entre a agricultura tradicional e a moderna. Na visão do autor, isso significava identificar as questões principais que condicionam a passagem de uma agricultura cujas técnicas do trabalhador rural são as mesmas que foram herdadas de seus antepassados para um modelo que passa a incorporar o conhecimento científico.

Segundo Schultz, essa mudança seria uma questão de direcionar investimentos para a agricultura, "mas não é principalmente um problema de obtenção de capital. Antes, constitui um problema de determinar as formas que deve tomar esse investimento, formas que tornarão lucrativo investir na agricultura" (SCHULTZ, 1965, p. 16). Caso seja feito de modo rentável, o setor agrícola, da mesma forma que o industrial, tem o potencial de gerar retornos e contribuir para o desenvolvimento econômico.

Apenas introduzir fatores modernos de produção (maquinários e fertilizantes, por exemplo) na agricultura tradicional seria insuficiente. Proceder dessa forma aumentaria os custos na medida em que esses fatores dificilmente seriam manejados da forma mais eficiente.

A variável-chave para modernizar a agricultura, para Schultz (1965), está no investimento no agente humano, ou seja, no nível de capacidade adquirida pelo pessoal agrícola. As habilidades do trabalhador rural, assim "como bens de capital, são meios de produção produzidos" (SCHULTZ, 1965, p. 178). Elas, entretanto, não obedecem às formas tradicionais de reprodução do capital, sendo alcançadas por meio de ganhos no que o autor define como "capital humano", o que a associa diretamente ao aprimoramento no grau de instrução dos empregados, treinamentos e melhorias na esfera da saúde e educação (SCHULTZ, 1965, p. 179).

Nessa linha de pensamento, ao compararmos produções agrícolas com distintos patamares de modernização, as diferenças em relação à qualidade da terra teriam um grau de importância menor; as diferenças na qualidade do capital material inserido teriam um grau intermediário; e as diferenças na capacidade do pessoal agrícola seriam aquelas de maior importância (SCHULTZ, 1965, p. 27).

A ideia é analisar como as regiões podem incorporar o capital humano à atividade agrícola. Para isso, fazemos uma divisão em duas formas: fatores de reprodução e de atração.

A reprodução do capital humano depende da inclusão, nos trabalhadores, de três elementos: uma educação formal, sobretudo, por meio do ensino superior; uma educação informal obtida na estrutura familiar e no entorno social, onde compreende-se os valores culturais da região; e uma experiência construída no trabalho e na execução de tarefas (GIMÉNEZ, 2005, p. 109).

Essas características, no entanto, não podem ser fortalecidas de forma isolada. Pelo contrário, avanços nessa área estão diretamente ligados ao desenvolvimento econômico, à urbanização e à interação com as atividades produtivas. Com efeito, as habilidades dos trabalhadores não se espalham no território de forma homogênea, mas estão atreladas aos setores econômicos que particularizam os locais (STORPER; SCOTT, 2008, p. 158). As técnicas incorporadas ao trabalho dependem da dinâmica local, que, de um lado, deve contar com a presença 
de centros de pesquisa e um sistema universitário de qualidade, de outro, com o engajamento das firmas em projetos de inovação e a disposição em destinar recursos para investir na mão de obra. Desse modo, a construção das habilidades acaba por se correlacionar à atividade econômica local ou regional.

A obtenção de mão de obra qualificada também pode ser pensada em relação aos fatores de atração. Nesse caso, temos como ênfase a escala nacional, com o movimento interno de trabalhadores nas fronteiras do país. Esse é um processo que Santos (1993) e Elias (2006) denominam "migração descendente", o que define a saída dos trabalhadores qualificados de centros urbanos tradicionais em direção às novas regiões de expansão do agronegócio para realização de serviços especializados. Eles se movem tanto para a esfera produtiva da agricultura e do setor agroindustrial quanto para novos serviços urbanos.

Junto à atração desses profissionais, devese pensar na capacidade dos locais em retê-los. Esse fator depende do potencial da cidade em oferecer uma infraestrutura urbana propícia com serviços de qualidade na área de saúde e educação; ter atrações culturais; e uma vida recreativa com parques, bares e restaurantes (FLORIDA, 2002).

Ao expandir para Goiás, de forma mais consistente, na segunda metade da década de 2000, a agroindústria canavieira confrontaria diretamente um desafio. A mão de obra qualificada era escassa; os fatores de reprodução eram insuficientes para atender toda a demanda que se criava; e, haviam poucos fatores de atração para reter os trabalhadores de fora que não fosse aumentar os salários.

Antes de aprofundar nessa questão, cabe discorrer sobre a intensidade com que a agroindústria canavieira cresceu em Goiás e interferiu na geração local de empregos.

\section{A EXPANSÃO DA AGROINDÚSTRIA CANAVIEIRA EM GOIÁS ENTRE 2006 E 2013}

Entre as safras de 2000/2001 e 2006/2007, a produção de etanol passou de $318 \mathrm{mil} \mathrm{m}^{3}$ para 822 mil $\mathrm{m}^{3}$. Na safra seguinte, esse valor saltou para $1.214 \mathrm{mil} \mathrm{m}^{3}$; em 2013/2014, já atingiu um total de $3.879 \mathrm{mil} \mathrm{m}^{3}$ (UNICA, 2015). Goiás presenciou um aumento de quase cinco vezes da produção de etanol em apenas sete safras. No tocante ao açúcar, esse crescimento é menos intenso e concentrado em poucas usinas, mas vem ganhando força nos últimos anos. A partir da safra de 2008/2009, a produção de açúcar em Goiás passa de 958 mil toneladas para 1.891 mil toneladas, na safra de 2013/2014 (UNICA, 2015).

Junto a esse processo, tem-se um elevado aumento na produção de cana-de-açúcar. Entre as safras de 2000/2001 a 2006/2007 a quantidade produzida, em Goiás, saltou de 7.208 mil toneladas para 16.140 mil toneladas. Um aumento de $124 \%$. Desde então, até a safra de 2013/2014, a produção de cana-de-açúcar aumentou de $284 \%$ atingindo um total de 62.018 mil toneladas. (UNICA, 2015).

Como indica a Figura 01, existe uma estreita correlação entre a expansão da cana-de-açúcar e o aumento da produção de etanol. 
Figura 01: Estado de Goiás: evolução da quantidade produzida de cana-de-açúcar e etanol, safras de $2000 / 2001$ a $2013 / 2014$.

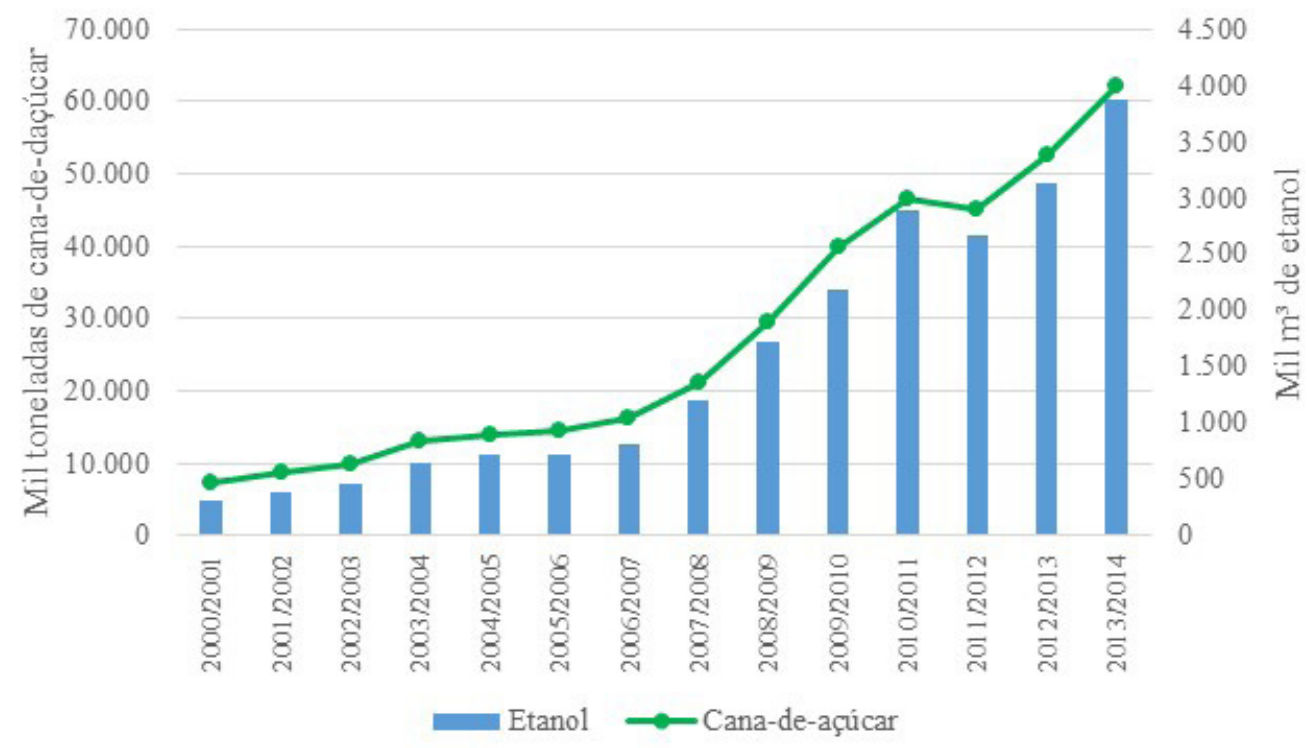

Fonte: Org. do autor a partir de UNICA (2015)

Como é conhecido, a agroindústria depende de uma proximidade entre a zona de cultivo e o local de processamento. Essa relação pauta-se por uma distância que, de um ponto de vista geométrico, compreende um raio de cerca de $40 \mathrm{~km}$ e, por uma questão de tempo, cerca de 36 horas na colheita manual ou poucas horas na colheita mecânica até o processamento (CASTILLO, 2013, p. 77). Com efeito, tem-se um elevado crescimento no número de unidades produtivas. Em 2005, haviam cerca de 15 usinas de açúcar e etanol em operação em Goiás. Em um curto intervalo de tempo, de 2006 a 2013, esse total saltou para próximo de 40 usinas. Somente no ano de 2009 dez novos empreendimentos foram iniciados na região.

As razões para o crescimento da agroindústria canavieira em Goiás se devem a uma combinação de fatores. Em meados de 2000, uma mudança na legislação de São Paulo, estipulou "procedimentos, proibições, regras de execução e medidas de precaução a serem tomados quando do emprego do fogo em práticas agrícolas" (MORAES, 2007, p. 608), fazendo com que fosse necessário aos produtores investir em estratégias para a mecanização. Com isso, tem-se uma reconfiguração nas vantagens locacionais do setor: regiões de solos com alta disponibilidade de nutrientes, mas de fácil compactação e com topografia acidentada, diminuíam sua atratividade, ao passo que, regiões de solos com menor disponibilidade de nutrientes, mas com topografia plana e maior estabilidade dos agregados - como os latossolos vermelhos que se estendem pelo sul de Goiás - passavam a figurar entre os mais atrativos.

Essa vantagem, que Goiás tinha para a agroindústria canavieira, não trouxe efeitos imediatos, mas se tornaria essencial com a situação que se criou diante do aumento na demanda por etanol a partir de 2003, com a entrada dos veículos flex-fuel no mercado. Na época, aumentar o número de usinas em São Paulo se mostrava inviável (CGEE, 2005). O nível de concentração do setor em algumas localidades do Estado gerava externalidades negativas que se manifestavam por uma demanda das usinas por cana maior do que aquela que a região era capaz de suprir, associada a uma concentração econômica, com o domínio de grupos empresariais sobre algumas regiões (FIGUEIRA; PEDROSA; 
BELIK, 2013, p. 24).

A expansão da agroindústria canavieira para novas áreas seria beneficiada pelo momento favorável que a economia brasileira atravessou na segunda metade da década de 2000, o que possibilitou a ampliação das linhas de crédito, sobretudo, no âmbito do Banco Nacional de Desenvolvimento Econômico e Social (BNDES). O Governo de Goiás também atuaria diretamente no sentido de atrair usinas com o lançamento do Programa Produzir, concedendo incentivos fiscais e, indiretamente, com Programa Rodovida, que tem aprimorado as rodovias no interior do Estado, otimizando a mobilidade no transporte da cana-de-açúcar.

Paralelamente, as pesquisas conduzidas pelo IAC, CTC e Ridesa, em especial, junto à usina Jalles Machado, de Goianésia, indicavam que a cana-de-açúcar em Goiás poderia atingir patamares de produtividade próximos - ou mesmo superiores - aos de São Paulo, caso fosse manejada de forma adequada com o uso de novas variedades e técnicas (MESQUITA, 2015). Em conjunto, esses centros de pesquisa iniciavam trabalhos de melhoramento genético para a criação de variedades apropriadas às condições da região, reforçando o caráter de Goiás como uma área de expansão.

A partir da segunda metade dos anos de 2000, cresce os investimentos em novas unidades produtivas em Goiás. Nesse contexto, destaca-se: os grupos tradicionais paulistas Cosan (que depois de 2011 cria a joint-venture Raízen, junto à Shell do Brasil), São João, Cerradinho e São Martinho; grupos externos ao setor, como a BP Biocombustíveis e a Odebrecht Agroindustrial; e grupos que formaram joint ventures para explorar a área, como a Cargill e a Petrobrás Bioenergia. Além desses, alguns grupos que estavam em Goiás previamente, como o Grupo Agromen (proprietário da Vale do Verdão), o Grupo Otávio Lage (proprietário da Jalles Machado) e o Grupo Farias (proprietário da Vale Verde), aproveitaram-se do momento para expandir o número de usinas.

Na medida em que novas unidades produtivas eram instaladas em Goiás, um efeito direto estava no aumento no número de empregos relacionados à agroindústria canavieira. Passamos, assim, para a análise desse processo.

\section{DINÂMICA DO EMPREGO NA AGROINDÚSTRIA CANAVIEIRA EM GOIÁS}

Por conta da proximidade geográfica entre a fase agrícola e industrial, o número de empregos criados pela agroindústria canavieira, em pouco tempo, superou o das demais atividades agrícolas e agroindustriais previamente localizadas em Goiás. Fazendo uma comparação com a soja, no ano de 2013, enquanto o somatório do emprego formal nas áreas de cultivo e processamento industrial atingiu um total 32.127 trabalhadores, na cana-de-açúcar, esse valor foi de 74.832 (RAIS, 2015). Isso mesmo levando em conta que, em 2013, a área colhida com soja em Goiás foi 3,4 vezes maior do que a com canade-açúcar (IBGE-PAM, 2015).

O crescimento do emprego na agroindústria canavieira refere-se a um avanço conjunto dos segmentos de cultivo da cana-de-açúcar e da produção de açúcar e etanol. Esse processo é ilustrado pela Figura 02. 
Figura 02: Estado de Goiás: evolução do emprego no cultivo da cana-de-açúcar e na fabricação de etanol e açúcar, 2006 a 2013.

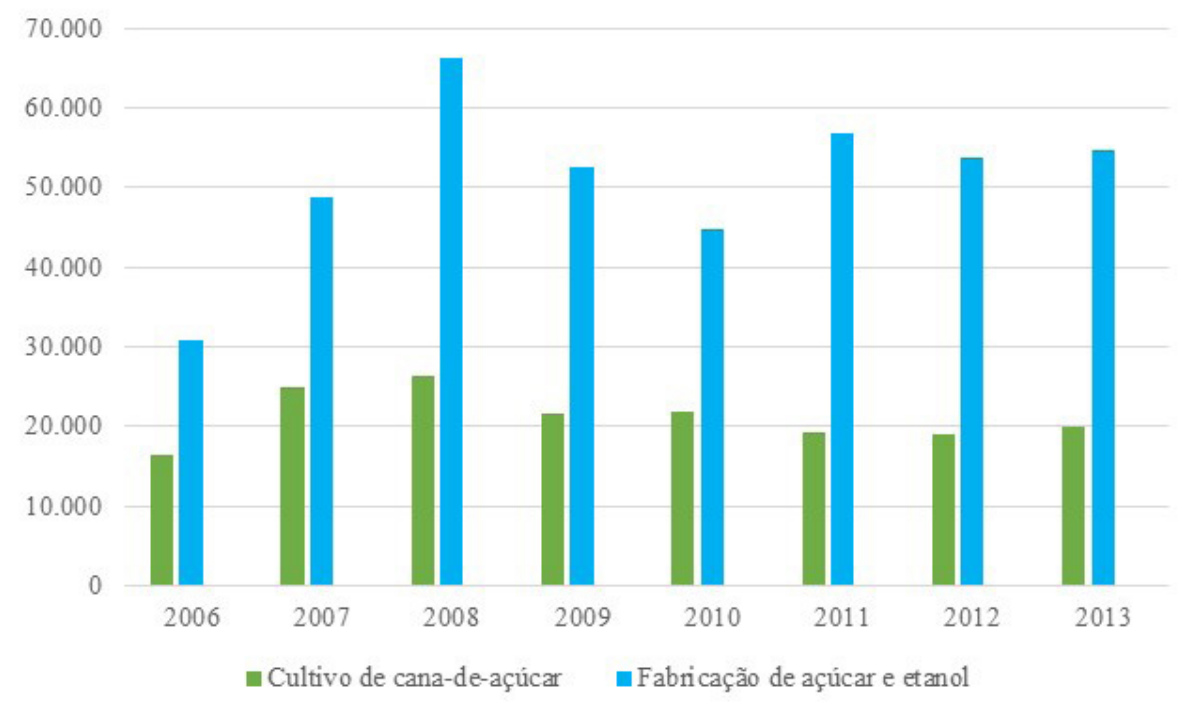

Fonte: Org. do autor a partir de Rais (2015).

A figura indica que mudanças importantes ocorreram entre 2006 e 2013. Tem-se um rápido crescimento de 2006 a 2008, quando se atinge um pico tanto na fase industrial quanto agrícola. Após os efeitos da crise internacional, esse valor sofre uma queda em 2009 e 2010, recuperando-se a partir de então, sobretudo, na fabricação de açúcar a etanol. Se nos atermos apenas à comparação do ano de 2006 com o de 2013, ambas as áreas aumentaram: o emprego na fabricação de açúcar e etanol, cresce $76,8 \%$, e no cultivo de cana-de-açúcar, $22,6 \%$.

Embora menos expressivo, o aumento na geração de emprego no cultivo da cana-de-açúcar merece maior reflexão. $\mathrm{O}$ dado de Goiás representa um movimento inverso ao que ocorreu no Brasil em tempos de mecanização da colheita e do plantio e consequente queda do corte manual. Em São Paulo, por exemplo, o cultivo da cana-de-açúcar, entre 2006 e 2013 , registrou uma redução de 247,2 mil para 146,7 mil empregados. Goiás tem uma elevação nesse número na medida em que o crescimento produção de cana-de-açúcar ocorreu quando a mecanização já havia se tornado uma realidade para o setor e o ambiente natural facilitava esse procedimento. Com isso, foi comum que as lavouras canavieiras fossem planejadas para a mecanização, reduzindo, de início, o volume de contrações. Em 2012, Goiás teve a maior taxa nacional de mecanização do plantio, $90 \%$, e a segunda maior da colheita, $88 \%$, atrás apenas do Mato Grosso do Sul (CTC, 2012, p. 14).

Nesse contexto, a agroindústria canavieira passou a demandar um maior volume de mão de obra qualificada. Esse fato é facilmente identificado quando percebe-se que, de 2006 a 2013, o número total de empregados no setor aumentou em 57,9\%, enquanto aqueles com ensino superior cresceram $452,8 \%$.

É certo que esse não é um movimento exclusivo de Goiás. Nopaís como um todo, a proporção dos trabalhadores com diploma universitário na agroindústria canavieira passou de 1,4\% em 2006 para 3,2\% em 2013. Em São Paulo, a variação, nesse mesmo período, foi de 1,9\% para 4,3\%. Em Goiás, entretanto, a mudança foi mais acelerada, passando de $1,3 \%$ para $4,4 \%$ (RAIS, 2015).

Basicamente, o que define a contratação de trabalhadores com maior grau de qualificação são os projetos para ampliar a produtividade da cana-deaçúcar. Esse é um trabalho que precisa ser feito de forma específica para o ambiente natural de cultivo 
da usina (HASEGAWA, 2005, p. 62). A cana-deaçúcar, por ser uma cultura semi-perene - ou seja, com um média de cinco cortes e seis anos antes de um novo plantio - assume maior dependência das condições edafoclimáticas locais. $\mathrm{O}$ aprofundamento do sistema radicular faz com que as camadas mais profundas do solo interfiram na produtividade, sobretudo, se contarem com alto teor de alumínio (LANDELL et al., 2003). A manutenção por um longo tempo no campo - em geral um ano ou um ano e meio - antes da colheita, faz com que a planta esteja vulnerável às variações no regime de chuvas e ao aumento na taxa de evapotranspiração. Assim sendo, da mesma forma como as condições de solo e clima variam de local para local, as formas de lidar com elas também variam.

Ao colocar como meta um crescimento vertical, o produtor precisa interagir com centros que desenvolvem pesquisas sobre a cana-de-açúcar, por exemplo, o IAC, CTC e a Ridesa, para criação de técnicas modernas e específicas. As consultorias feitas por esses centros auxiliam na seleção das variedades mais apropriadas ao seu ambiente natural e o manejo necessárias ao cultivo.

Para essas parcerias serem eficientes, são necessários técnicos com conhecimento previamente acumulado sobre a cana-de-açúcar. Nesse processo, os trabalhadores locais não precisam estar aptos apenas para internalizar novos aprendizados, mas adaptá-los às suas condições naturais. Cabe a eles observar o desempenho da variedade; ver em que medida a planta resiste às pragas e doenças locais; analisar se o perfilhamento está adequado para a colheita mecanizada; e identificar a resposta da planta à irrigação e ao estresse hídrico do local.

Um ponto central é que a capacidade de obtenção desses trabalhadores é bastante heterogênea. As usinas não estão engajadas da mesma forma na busca por inovações para ampliar a produtividade. Apenas uma parte coloca como prioridade investir na melhoria do pessoal agrícola.

Para uma análise dessas distinções é necessário olhar para o nível local. Para tanto, utilizamos a base de dados da Rais na desagregação dos municípios de Goiás.

Consideramos, em primeiro lugar, o somatório do emprego formal nas classes da Classificação Nacional de Atividades Econômicas (CNAE) 2.0: cultivo de cana-de-açúcar, fabricação de açúcar em bruto, fabricação de açúcar refinado e fabricação de álcool. Em segundo, dividimos o emprego em três grupos distintos de escolaridade: (i) fundamental, incluem-se analfabetos, pessoas com o quinto ano incompleto, quinto ano completo, do sexto ao nono ano do fundamental, fundamental completo e ensino médio incompleto; (ii) médio, incluem-se pessoas com ensino médio completo e superior incompleto; (iii) superior e pós-graduação, que agrupa trabalhadores que concluíram o ensino superior e aqueles que têm título de mestrado e doutorado. Em terceiro lugar, fazemos o cálculo da média nos anos de 2011, 2012 e 2013 com o intuito de obter resultados mais consolidados e evitar efeitos anuais. Em quarto, excluímos da análise os municípios onde o total do emprego atingiu um valor inferior a 1.000 .

Chegamos, assim, a um total de 26 municípios, os quais, foram divididos em dois grupos:

- Grupo I: aqueles que mais de 3,5\% do total de empregados estão na classe "superior e pósgraduação". Inclui os municípios de Edeia, Mineiros, Perolândia, Itumbiara, Turvelândia, Quirinópolis, Jataí, Vicentenópolis, Caçu, Anicuns, Goiatuba, Chapadão do Céu, Goianésia

- Grupo II: aqueles que menos de $3,5 \%$ do total de empregados estão na classe "superior e pósgraduação". Inclui os municípios de Porteirão, Jandaia, Rio Verde, Morrinhos, Marilândia, Serranópolis, Santa Helena de Goiás, Rubiataba, Itapuranga, São Patrício, Ipameri, Itapaci, Inhumas

A Tabela 01 indica o resultado obtido a partir desse procedimento de análise na média dos anos de 2011, 2012 e 2013. 
Tabela 01: Estado de Goiás: grau de escolaridade na agroindústria canavieira (média de 2011 a 2013 do emprego formal)

\begin{tabular}{|c|c|c|c|c|c|c|c|c|}
\hline \multirow[t]{2}{*}{ Municípios } & \multicolumn{2}{|c|}{ Fundamental } & \multicolumn{2}{|c|}{ Ensino médio } & \multicolumn{2}{|c|}{$\begin{array}{l}\text { Superior e pós- } \\
\text { graduação }\end{array}$} & \multicolumn{2}{|l|}{ Total } \\
\hline & Média & $\%$ & Média & $\%$ & Média & $\%$ & Média & $\%$ \\
\hline \multicolumn{9}{|l|}{ Grupo I } \\
\hline Edeia & 963 & 62,9 & 451 & 29,5 & 116 & 7,6 & 1.530 & 100,0 \\
\hline Mineiros & 1.734 & 58,2 & 1.021 & 34,3 & 223 & 7,5 & 2.979 & 100,0 \\
\hline Perolândia & 972 & 50,8 & 821 & 42,8 & 123 & 6,4 & 1.916 & 100,0 \\
\hline Itumbiara & 2.110 & 65,6 & 922 & 28,7 & 182 & 5,7 & 3.215 & 100,0 \\
\hline Turvelândia & 1.462 & 71,1 & 481 & 23,4 & 112 & 5,5 & 2.055 & 100,0 \\
\hline Quirinópolis & 4.198 & 61,2 & 2.300 & 33,5 & 363 & 5,3 & 6.862 & 100,0 \\
\hline Jataí & 1.694 & 68,7 & 647 & 26,2 & 125 & 5,1 & 2.466 & 100,0 \\
\hline Vicentinópolis & 940 & 63,6 & 465 & 31,5 & 73 & 4,9 & 1.478 & 100,0 \\
\hline Caçu & 1.988 & 65,5 & 905 & 29,8 & 144 & 4,8 & 3.037 & 100,0 \\
\hline Anicuns & 3.138 & 81,6 & 551 & 14,3 & 154 & 4,0 & 3.843 & 100,0 \\
\hline Goiatuba & 3.128 & 71,4 & 1.077 & 24,6 & 175 & 4,0 & 4.380 & 100,0 \\
\hline Chapadão do Céu & 1.817 & 83,8 & 266 & 12,3 & 85 & 3,9 & 2.168 & 100,0 \\
\hline Goianésia & 4.841 & 69,5 & 1.866 & 26,8 & 260 & 3,7 & 6.967 & 100,0 \\
\hline \multicolumn{9}{|l|}{ Grupo II } \\
\hline Porteirão & 1.012 & 80,7 & 202 & 16,1 & 41 & 3,3 & 1.255 & 100,0 \\
\hline Jandaia & 1.033 & 74,0 & 321 & 23,0 & 41 & 3,0 & 1.396 & 100,0 \\
\hline Rio Verde & 653 & 63,6 & 344 & 33,5 & 30 & 2,9 & 1.026 & 100,0 \\
\hline Morrinhos & 1.281 & 70,5 & 487 & 26,8 & 50 & 2,8 & 1.818 & 100,0 \\
\hline Marilândia & 1.349 & 84,8 & 199 & 12,5 & 44 & 2,7 & 1.591 & 100,0 \\
\hline Serranópolis & 1.028 & 81,0 & 207 & 16,3 & 34 & 2,7 & 1.269 & 100,0 \\
\hline Santa Helena de Goiás & 3.050 & 79,5 & 703 & 18,3 & 83 & 2,2 & 3.835 & 100,0 \\
\hline Rubiataba & 1.984 & 67,6 & 890 & 30,3 & 59 & 2,0 & 2.933 & 100,0 \\
\hline Itapuranga & 850 & 80,4 & 187 & 17,7 & 21 & 2,0 & 1.057 & 100,0 \\
\hline São Patrício & 1.635 & 79,5 & 391 & 19,0 & 29 & 1,4 & 2.055 & 100,0 \\
\hline Ipameri & 962 & 86,9 & 130 & 11,7 & 15 & 1,3 & 1.106 & 100,0 \\
\hline Itapaci & 2.812 & 82,3 & 559 & 16,4 & 45 & 1,3 & 3.416 & 100,0 \\
\hline Inhumas & 1.577 & 89,9 & 160 & 9,1 & 18 & 1,0 & 1.755 & 100,0 \\
\hline
\end{tabular}

Fonte: Org. do autor a partir de Rais (2015). 
Nos municípios que compõe o Grupo I, é interessante destacar que os quatro com maior porcentagem de empregados com ensino superior e/ ou pós-graduação são áreas de influência de usinas pertencentes a grupos externos ao setor canavieiro. Edeia e Itumbiara são localidades onde estão as plantas da BP Biocombustíveis. Em Mineiros e Perolândia estão plantas da Odebrecht Agroindustrial. Turvelândia e Jataí, que são, respectivamente, o quinto e o sétimo com maior percentual dessa classe de trabalhadores, indicam a atuação do grupo paulista Vale do Verdão e da Raízen. Quirinópolis, que está em sexto, reflete os esforços das joint ventures SJC Bioenergia (Grupo Usina São João e Cargill) e Nova
Fronteira Bioenergia (São Martinho e Petrobrás Bioenergia).

Ao mesmo tempo, persistem municípios (Grupo II) onde o percentual desse tipo de empregado é baixo. Nesse caso, os de menor porcentagem são: Inhumas, onde está a usina Centroálcool; Itapaci, área de influência de uma unidade da Vale Verde; e Ipameri, relacionada à usina Lasa.

A Figura 03 estabelece o cálculo da produtividade na cana-de-açúcar no conjunto de municípios que representam os Grupos I e II, buscando identificar, nessa diferenciação, um elo entre a produtividade e os investimentos em trabalho qualificado.

Figura 03: Estado de Goiás: variação da produtividade da cana-de-açúcar no conjunto dos municípios dos Grupos I e II entre 2006 e 2013

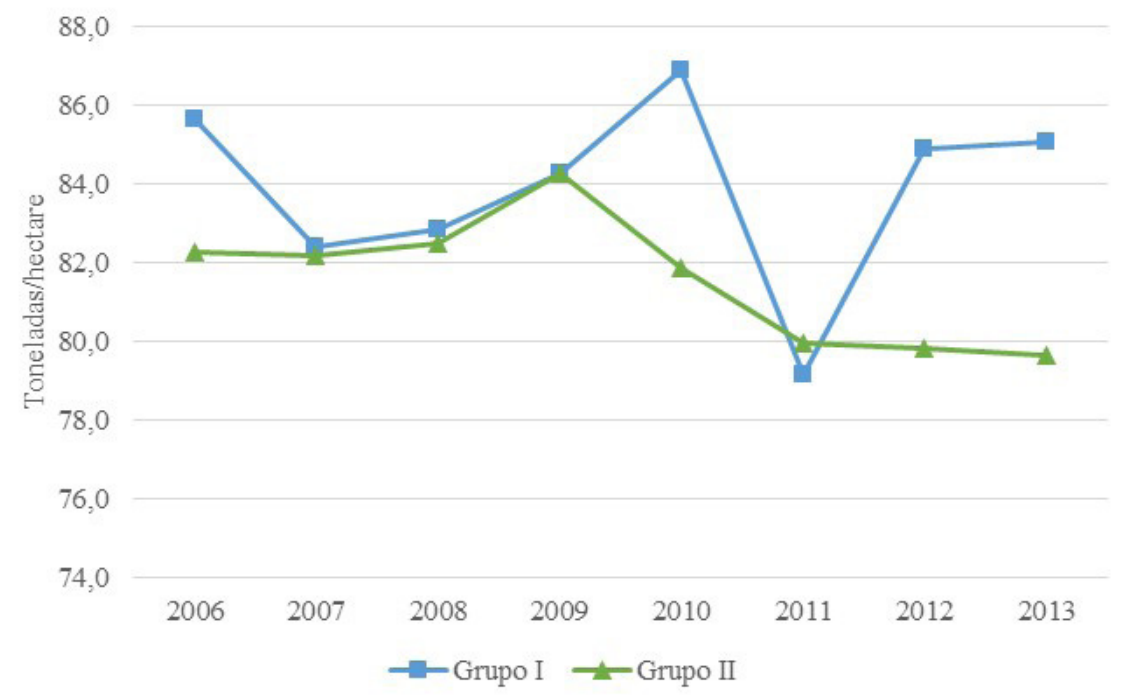

Fonte: Org. do autor a partir de IBGE-PAM (2015a).

Nota-se que a trajetória da produtividade dos municípios que compõem os Grupos I e II foram semelhantes entre 2007 e 2009, momento em que muitas das usinas iniciavam os projetos de instalação. Em 2010, o Grupo I teve um alto crescimento e uma forte queda em 2011. Essa retração, mais intensa em Edeia e Mineiros, ilustra um problema comum na expansão na expansão dos Cerrados. Muitas usinas (o caso desses dois municípios é ilustrativo por serem áreas de influências de usinas, até então, de fora do setor canavieiro) levaram para Goiás um receituário de cultivo e manejo próprio de outros ambientes sem se atentar para as mudanças que as condições do Cerrado requeriam. Quando isso é feito, é comum que os dois primeiros cortes tenham produtividade boas, entretanto, a partir do terceiro o produtor confronta com uma forte queda (LANDELL et al. 2003).

Essa perda criou um alerta sobre a necessidade de inovar e destinar maiores recursos a qualificação da mão de obra na região. Como ilustra a figura 03 , aqueles que seguiram esse caminho (Grupo I) conseguiram recuperar o índice de produtividade atingindo a casa de 85,0 t/ha em 2013, enquanto, os que pouco investiram (Grupo II) se estagnaram em 
um valor médio de 79,6 t/ha nesse mesmo ano.

Ficava cada vez mais claro a importância da mão de obra para ser rentável investir em Goiás. A questão era como adquirir esses trabalhadores.

\section{EVOLUÇ̃̃O DAMÃO DE OBRAQUALIFICADA EM GOIÁS}

A busca por mão de obra qualificada na agroindústria canavieira em Goiás antecede a expansão do setor na segunda metade de 2000. Esse movimento foi marcante no início dos projetos de mecanização da colheita e plantio da cana-deaçúcar em usinas como a Goiasa, em Goiatuba e a Jalles Machado, em Goianésia. Nessa época, já era evidenciado o problema da carência de mão de obra.

Poucos trabalhadores locais estavam aptos para operar as colhedoras, o que gerava problemas na medida em que falhas na condução das máquinas podiam compactar o solo ou danificar a touceira da planta, resultando em perdas significativas de produtividade para os próximos cortes. Com isso, avançou uma primeira busca por empregados de São Paulo para trabalhar na região. Entretanto, por ser um movimento particular de algumas usinas e ser realizado em uma época que a escala produtiva era pequena, poucas mudanças foram geradas nessa fase.

A maior procura por trabalhadores qualificados acompanha o novo panorama da agroindústria canavieira da segunda metade da década de 2000. À época, com a vinda de novas usinas para Goiás, além de ampliar a procura por operadores de colheitadeiras e plantadeiras, criou-se uma demanda por profissionais das ciências agrárias relacionados à área de manejo da cana-de-açúcar e por técnicos especializados em áreas, como, por exemplo, na manutenção de tratores, aplicação de herbicidas, inseticidas e pesticidas.

Era essencial que a aquisição de trabalhadores qualificados fosse feita de forma integrada no âmbito da fase agrícola. Pouco adiantava um denso trabalho na seleção de variedades modernas se, na aplicação do herbicida, fosse utilizada uma quantidade superior à requerida para o local. Pouco adiantava selecionar as melhores variedades e usar a quantidade correta de herbicida se, na hora da colheita, o operador colocasse a velocidade da colheitadeira acima da necessária para aquela área e prejudicasse o próximo ciclo.

A primeira opção de muitas usinas para atrair esses profissionais foi ampliar a leva de "migração descendente" de São Paulo para Goiás - evento particularmente claro nas usinas controladas por grupos paulistas. Entretanto, nesse caso, era comum o problema da adaptação aos modos de vida do interior goiano. As pequenas cidades da região não forneciam fatores de atração, como serviços locais para reter essas pessoas. Dos 26 municípios ilustrados na tabela 1 , apenas cinco possuíam, no ano de 2010, uma população superior a 50 mil habitantes. Em oito desses casos (Serranópolis, Vicentinópolis, Chapadão do Céu, Jandaia, Turvelândia, Porteirão, Perolândia e São Patrício) esse valor não atingia 10 mil habitantes (IBGE-CD, 2015).

Assim, era frequente que os trabalhadores de fora não criassem laços com a região, deixando-a assim que outras oportunidades surgiam. Essa saída aumentava a rotatividade do trabalho e prejudicava a continuidade de projetos. Em alguns casos também se contesta o fato das habilidades dos trabalhadores externos estarem relacionadas ao aprendizado sobre condições distintas, como as de São Paulo, por exemplo (MESQUITA, 2015). Ou seja, era necessário prepará-los para a nova realidade, algo nem sempre fácil de ser feito.

Uma segunda opção - utilizado sobretudo pelos novos grupos empresariais - foi contratar profissionais que já estavam nas usinas previamente instaladas na região. Esse tipo de trabalhador se tornou disputado, pois detinha o conhecimento da produção local e estava adaptado aos modos de vida. Porém, além de escassos, nem todos estavam dispostos a mudar de usina. Ademais, essa alternativa não resolvia o problema da mão de obra, mas apenas o transferia de lugar.

A primeira e segunda opções acarretavam em dispêndios para as usinas, pois elas precisavam ampliar os gastos com salários para atrair novos empregados. Essas medidas não eram sustentáveis para um crescimento nas dimensões que Goiás presenciou. Caso fosse feito dessas duas formas, o peso do salário dos profissionais qualificados afetaria 
o orçamento das usinas, reduzindo a rentabilidade dos investimentos na região. Além do mais, também aumentaria a dependência que os usineiros teriam de um reduzido número de trabalhadores.

Caminhou-se, assim, rumo a uma terceira opção: a reprodução interna do capital humano. Para o setor produtivo, isso era algo conveniente, pois permitia superar os problemas das opções anteriores com a formação de trabalhadores preparados para as condições de produção no Cerrado e com maiores laços com a região. Ao mesmo tempo, o aumento da oferta local teria uma pressão para reduzir os salários. Pelo lado da população, era importante o fato da agroindústria canavieira gerar um maior volume de empregos em relação a muita das atividades econômicas previamente instaladas. Pelo lado do governo e das prefeituras, observou-se que esse era um passo central para ampliar a atração de novas usinas, criando uma vantagem competitiva de Goiás em comparação com os demais Estados das novas regiões de fronteira da cana-de-açúcar.

A formação desses profissionais atrelase à evolução do sistema universitário local. No caso, a principal força é a Universidade Federal de Goiás (UFG), que destaca-se no âmbito do CentroOeste pela alta interação com o setor produtivo (ALMEIDA; POVOA, 2011, p. 415). De seus 298 grupos de pesquisa, um total de 56 , o que equivale a $18,8 \%$, relataram ter vínculos ao menos com uma empresa (CNPQ, 2015a).

Contribuiu, nesse processo, o fato de a UFG tornar-se uma das unidades da Ridesa em 2004. Esse programa, vinculado ao melhoramento genético da cana-de-açúcar, refere-se a uma continuidade do trabalho do antigo Programa Nacional de Melhoramento da Cana-de-Açúcar (Planalsucar), encerrado em 1990. A Ridesa se organiza com base em uma rede universidades federais que atualmente inclui, além da UFG, a UFPR, UFSCar, UFV, UFRRJ, UFSE, UFAL, UFRPE, UFPI e UFMT (FURTADO; SCANDIFFIO; CORTEZ, 2011, p. 162). Ao criar a sede de Goiás, os pesquisadores da Ridesa da UFG ficaram responsáveis pelos testes das variedades desse programa na região e por iniciar o desenvolvimento uma variedade específica para a região.

Além da Ridesa, ressaltamos a presença de quatro grupos de pesquisa da UFG que tem trabalhado na área de cana-de-açúcar. Nas ciências agrárias: o grupo melhoramento de plantas, que atua na genética e adaptação das culturas - algodão, canade-açúcar, milho, soja, arroz e espécies nativas do Cerrado - às condições locais, tendo parcerias com usinas canavieiras; o grupo fitossanidade em soja e cana-de-açúcar em Goiás, que trabalha na análise e no controle de doenças nessas culturas; e o grupo Manejo Integrado de Pragas (MIP), que estuda essa situação nas culturas agrícolas da região. Nas ciências biológicas: o grupo biotecnologia de fungos, que trabalha com o melhoramento genético da canade-açúcar, fazendo uso de biotecnologia.

Fora de Goiás, mas com importância na região, destaca-se o grupo Silício na Agricultura, da Universidade Federal de Uberlândia (UFU), que desenvolve pesquisas sobre o silício nos solos, plantas e fertilizantes, sendo essencial na orientação do uso da vinhaça na cana-de-açúcar (CNPQ, 2015a).

A Ridesa e esses grupos de pesquisa foram centrais para avançar o processo de qualificação do pessoal agrícola em Goiás. É comum que muitos dos estudantes de graduação e pós-graduação que estão inseridos nos mesmos sejam contratados pelas usinas. Muitas vezes, esse elo é favorecido pela existência de parcerias entre a usina e a universidade para o desenvolvimento de trabalhos conjuntos que aliam teoria e prática no estudo de alguma questão específica de interesse da usina. Nesses casos, as usinas, em geral, disponibilizam terra e recursos (insumos e mão de obra) para realização de experimentos sobre a cana-de-açúcar. Com isso, desde o início, a formação dos recursos humanos era preparada para as condições particulares de Goiás e da usina.

Os cursos de Ciências Agrárias da UFG localizam-se em Goiânia e Jataí, ficando, assim, próximos das principais regiões produtoras de Goiás. Além dessa universidade, merece destaque a atuação da UEG que oferece o curso de graduação em Tecnologia em Produção Sucroalcooleira nas cidades de Mineiros e Edéia; e o curso de Agronomia em Ipameri e Palmeiras de Goiás.

Fortalece o campo das ciências agrárias, em Goiás, a presença de profissionais da área de ensino 
e pesquisa que apresentam o grau de doutorado. $\mathrm{Na}$ mesorregião do Centro Goiano, onde está a UFG, essa é a terceira área com maior número de professores doutores, tendo, em 2015, um total de 328 , o equivalente a $13,2 \%$ do total. No Sul Goiano, a área é a primeira com maior número de doutores. Dos 92 presentes nas instituições dessa mesorregião, 39, o que responde por $42,4 \%$ do total, estão relacionados às ciências agrárias (CNPQ, 2015b).

Nesse quesito, ainda cabe mencionar o papel de Brasília. A capital federal agrupa um volume significativo de cientistas com grau de doutorado dedicados ao ensino e à pesquisa na área de ciências agrárias. São 1.114 profissionais, o que representa 24,0\% do total em Brasília em 2015 (CNPQ, 2015b). Fortalecem essa linha as unidades da Empresa Brasileira de Pesquisa Agropecuária (Embrapa) e da Universidade de Brasília (UNB).

Pode-se inferir que a presença desses profissionais em Goiás e, de certa forma, em Brasília tem sido um elemento indutor da pesquisa local e, por conseguinte, da melhoria da mão de obra. Como coloca Storper (2013, p. 149), embora, eventualmente, cientistas possam participar de redes que extrapolam a área de localização de seus institutos, a tendência é que os resultados que eles produzam sejam locais. Ademais, nas ciências agrárias, as vantagens da proximidade com uma agricultura dinâmica, como a de Goiás, fortalecem o vínculo local entre produtores e pesquisadores para o acompanhamento dos projetos. Cabe lembrar que, no país, as ciências agrárias aparecem em segundo lugar - atrás apenas das engenharias - entre as áreas cujos grupos de pesquisa têm maiores vínculos com empresas (CNPQ, 2015a).

Embora estejamos enfatizando o ensino superior, não foi apenas nessa área que se aprofundou esforços de aperfeiçoamento. É importante destacar o treinamento específico que tem sido feito em escolas técnicas. O Serviço Nacional de Aprendizagem Industrial (Senai) oferece o curso "Açúcar e Álcool" em Itumbiara. O curso foi criado em 2008 por meio de uma parceria com a usina Alvorada, de Araporã (MG), para qualificação dos funcionários da empresa. Atualmente, além da Usina Alvorada, o curso criou parcerias com a BP Biocombustíveis, de Itumbiara, e a Goiasa, de Goiatuba. O Serviço Nacional de Aprendizagem Rural (Senar) de Goiás atua na realização de treinamentos para as atividades relacionadas, por exemplo, a operação e manutenção de colhedora de cana-de-açúcar; ao plantio mecanizado de cana-de-açúcar; e operação e manutenção de sistema de irrigação por aspersão.

As usinas eram as principais beneficiadas por esses procedimentos, pois colhiam os frutos das externalidades positivas geradas pelos esforços na região, em geral, feitos com investimentos do Estado. Mas, elas também têm participação direta nesse processo com a realização de treinamentos internos, oferecimento de bolsas de estudos para os trabalhadores realizarem a graduação e pósgraduação e buscando formar parcerias com as instituições de ensino e pesquisa.

\section{CONSIDERAÇÕES FINAIS}

$\mathrm{O}$ aumento dos profissionais com ensino superior representa um dos elos que permitiram o crescimento da agroindústria canavieira em Goiás, sobretudo, em termos qualitativos. Esse foi um ponto necessário na medida em que o aumento na demanda por açúcar e etanol refletia em medidas para aumentar a taxa de produtividade da cana-de-açúcar exigindo trabalhos mais complexos nas lavouras. Esse processo não é generalizado nas usinas da região, mas ocorre de forma mais intensa naquelas que investiram recursos para a pesquisa e melhoria da técnica de produção.

Para a expansão do setor canavieiro era necessário um tipo de trabalhador que otimizasse os laços com os centros de pesquisa. Eles precisavam identificar onde estavam as respostas negativas e positivas no manejo e internalizar o conhecimento sobre as condições de produzir no ambiente natural da usina. Fator, esse, central, já que não era prático recorrer aos centros todas as vezes que alguma dificuldade aparecia.

A aquisição desses profissionais foi difícil na medida em que os fatores de atração eram baixos e os fatores de reprodução acabaram sendo construídos junto à expansão da agroindústria canavieira. Aos poucos, a reprodução local minimizava, mas não 
solucionava o problema. Assim, mesmo tendo diminuído nos últimos anos, a escassez de mão de obra qualificada continua sendo uma preocupação recorrente do setor.

Essa questão, ao ser colocada em pauta, não pode ser vista apenas como "mais uma" entre as dificuldades que o setor enfrenta, mas, seguindo a perspectiva de Schultz (1965), é justamente o fator que está na essência da modernização da cana-deaçúcar e na forma de tonar economicamente rentável os investimentos na região.

\section{REFERÊNCIAS}

ALMEIDA, Carla C. R.; POVOA, Luciano M. C. Interações das universidades, institutos e centros de pesquisa com empresas na região Centro-Oeste: a experiência da Embrapa Cerrados. In: SUZIGAN, Wilson; ALBUQUERQUE, Eduardo da M.; CARIO, Silvio A. F. (Org.). Em busca da Inovação: Interação universidade-empresa no Brasil. Belo Horizonte: Autêntica Editora, 2011.

CASTILlO, Ricardo. A expansão do setor sucroenergético no Brasil. In: BERNARDES, Júlia A.; SILVA, Catia A.; ARUZZO, Roberta. C. (Org.) Mudanças no paradigma sucroenergético. Rio de Janeiro: Lamparina, 2013.

CENTRO DE GESTÃO E ESTUDOS ESTRATÉGICOS - CGEE. Estudo sobre as possibilidades e impactos da produção de grandes quantidades de etanol visando à substituição parcial de gasolina no mundo. Relatório Final, Campinas: Unicamp, 2005.

CONSELHONACIONALDEDESENVOLVIMENTO CIENTÍFICO E TECNOLÓGICO - CNPQ. Diretório dos Grupos de Pesquisa do Brasil. Disponível em $<$ http://goo.gl/F6OQYh>. Acesso em: 10 fev. 2015a.

Painel Lattes. Disponível: <http://goo.gl/ FSk7Dg $>$. Acesso em: 10 fev. 2015 b.

CENTRO DE TECNOLOGIA CANAVIEIRA - CTC. Censo Varietal e de produtividade: Região Centro-Sul.
2012. Disponível em <http://goo.gl/y56S8r $>$. Acesso em: 15 abr. 2015.

ELIAS, Denise. Globalização e fragmentação do espaço agrícola do Brasil. Scripta Nova. Barcelona. v. 10, n. 218. 2006. Disponível em <http://goo.gl/ RJiq1I $>$. Acesso em: 12 jul. 2011.

FIGUEIRA, Sérgio R. F.; BELIK, Walter; VICENTE, Andrea K. Escala e concentração das usinas de açúcar e álcool e empresas do setor no Estado de São Paulo. In: CONGRESSO DA SOCIEDADE BRASILEIRA DE ECONOMIA, ADMINISTRAÇÃO E SOCIOLOGIA RURAL, 52. 2014. Anais... Goiânia: Sober. 2014. Disponível em <http://goo.gl/Br5HMH $>$. Acesso em: 15 nov. 2014.

FLORIDA, Richard. The economic geography of talent. Annals of the Association of American Geographers. Washington. v. 4, n. 92. 2002, p. 743755, 2002. Disponível em <http://goo.gl/5LxeRg > Acesso em: 14 mar. 2015. DOI: 10.1111/14678306.00314

FURTADO, André T.; SCANDIFFIO, Mirna I.; CORTEZ, Luis A. B. The Brazilian sugarcane innovation system. Energy Policy, v. 39. p. 156-166, 2011. DOI:10.1016/j.enpol.2010.09.023

GIMÉNEZ, Gregorio. La dotación de capital humano de América Latuna y el Caribe. Revista de la Cepal, Santiago, n. 86, p. 103-122. Disponível em $<$ http:// goo.gl/dAlwRs>. Acesso em: 23 jun. 2014.

GLOBO RURAL. Em Goiás, falta mão de obra para trabalhar nas usinas de cana. G1, Rio de Janeiro, 9 jun. 2014. Globo Rural. Disponível em <http://goo. gl/AFoPhj>. Acesso em: 12 mar. 2015.

HASEGAWA, Mirian. Avaliação das capacitações e dos spinoffs gerados por programas de $P \& D$ : $\mathrm{O}$ programa cana do IAC. 2005. 195 f. Tese (Doutorado em Política Científica e Tecnológica) Instituto de Geociências, Universidade Estadual de Campinas, Campinas, 2005. 


\section{INSTITUTO BRASILEIRO DE GEOGRAFIA E} ESTATÍSTICA - IBGE. PAM - Produção Agrícola Municipal. Disponível em: <http://goo.gl/2wNV30>. Acesso em: 30 abr. $2015 \mathrm{a}$.

. CD - Censo Demográfico. Disponível em: $<$ http://goo.gl/2wNV30>. Acesso em: 12 abr. 2015b.

LANDELL, Marcos G. A.; PRADO, Helio; VASCONCELOS, Antônio C. M.; PERECIN, Dilermando; ROSSETTO, Raffaella; BIDÓIA, Marco Aurélio P.; SILVA, Marcelo A.; XAVIER, Mauro A. Oxisol subsurface chemical attributes related to sugarcane productivity. Scientia Agricola, São Paulo, v. 60 , n. 4 , p.741-745, 2003. DOI: http://dx.doi. org/10.1590/S0103-90162003000400020

LIBONI, Lara B. Perfil da mão-de-obra no setor sucroalcooleiro: tendências e perspectivas. 2009. 201 f. Tese (Doutorado em Administração) - Faculdade de Economia, Administração e Contabilidade, Universidade de São Paulo, 2009.

MESQUITA, F. C. Evolução da agricultura e transformações da técnica e das relações territoriais no cerrado goiano: a dimensão endógena da expansão da agroindústria canavieira. 2015. 257 f. Tese (Doutorado em Geografia) - Instituto de Geociências, Universidade Estadual de Campinas, 2015.

RELAÇÃO ANUAL DE INFORMAÇÕES SOCIAIS - RAIS. 2015. Disponível em: <http://goo.gl/ cX1RnP $>$. Acesso em: 21 mar. 2015.

SANTOS, Milton. A urbanização brasileira. São Paulo: Hucitec, 1993.

SALLES-FILHO, Sergio M. Apresentação. Revista Brasileira de Inovação. Campinas. v. 4, n.1. 2005. Disponível em $<\mathrm{http} / /$ goo.gl/2tXkdt $>$. Acesso em: 12 jan. 2015.

MORAES, Márcia A. F. D. de. O mercado de trabalho da agroindústria canavieira: desafios e oportunidades. Revista de Economia Aplicada. Ribeirão Preto. v. 11, n. 4. p.605-609, 2007. DOI: http://dx.doi.org/10.1590/

\section{S1413-80502007000400008}

SCHULTZ, Theodore W. A Transformação da agricultura tradicional. Rio de Janeiro: Zahar, 1965. STORPER, Michael. Keys to the city. How Economics, Institutions, Social Interaction, and Politics Shape Development, Princeton e Oxford: Princeton University Press, 2013.

STORPER, Michael; SCOTT, Allen. J. Rethinking human capital, creativity and urban growth. Journal of Economic Geography, Oxford. v. 9, n. 2, p. 147167. 2008.

UNIÃO DA INDÚSTRIA DE CANA-DE-AÇÚCAR - UNICA. Dados e cotações. Disponível em $<$ http:// goo.gl/JjylH3>. Acesso em: 12 mai. de 2015.

YAMADA, Sho. Cadeia produtiva da cana-de-açúcar em Goiás e análise de desempenho em eficiência de sistemas produtivos. 2014. 94 f. Dissertação (Mestrado em Agronegócios) - Faculdade de Agronomia e Medicina Veterinária, Universidade de Brasília, 2014. 